\title{
Late Progression of Post-Encephalitic Parkinson's Syndrome
}

\author{
Donald B. Calne and Andrew J. Lees
}

\begin{abstract}
We have studied 11 patients with neurological deficits due to the pandemic of encephalitis lethargica, all of whom had remained in hospital for more than forty years. Retrospective information obtained from physicians and nurses dating back as far as 1931, our own Webster and Northwestern University Disability Rating Scales available from 1976, photographic records, published narrative and hospital charts all indicate that neurological disabilities attributable to basal ganglia damage frequently increase in late life. Deterioration was most marked in motor function and largely spared the intellect, special senses and somatosensory system. The findings are discussed in relation to current hypotheses concerning the aetiology of Parkinson's disease.
\end{abstract}

RÉSUMÉ: La progression en retard du syndrome parkinsonien post-encéphalitique. Nous avons étudié 11 patients montrant des troubles neurologiques entraînés par la pan-épidémie de l'encéphalite léthargique, qui sont restés hospitalisés depuis plus de 40 ans. D'après des renseignements rétrospectifs obtenus de médécins et d'infirmières depuis 1931, nos propres échelles d'invalidité de Webster et de l'université Northwestern qui sont disponibles depuis 1976, de documents photographiques, de procès-verbaux, et de dossiers médicaux, tous indiquent que les invalidités neurologiques attribués aux lésions du corps strié augmentent souvent à l'âge avancé. La détérioration est plus marquée dans le fonctionnement moteur et semble épargner la fonction intellectuelle, les sens spéciaux, et le système somatosensible. Les trouvées sont discutées en relation avec les hypothèses courantes concernant l'étiologie de la maladie de Parkinson.

Can. J. Neurol. Sci. 1988; 15:135-138

The pandemic of encephalitis lethargica (Von Economo's disease, Type A encephalitis) appeared suddenly in several isolated European pockets in 1919; it then spread throughout the world over the course of seven years with perhaps greater vigour and virulence than any other disease of the twentieth century, finally to disappear as suddenly as it had emerged. Rare, clinically identical cases continue to occur ${ }^{1}$ and the presence of local synthesis of IgG within the central nervous system is in keeping with a presumptive viral aetiology. ${ }^{2}$

Encephalitis lethargica is of particular interest because the extrapyramidal sequelae that occurred either immediately after the febrile illness or after a latency extending from a few months to several decades. To our knowledge there has been no previous report concentrating on the last phase of the natural history of the disorder, addressing specifically the period forty to sixty years after the acute infection and corresponding to the age range of 60-80 years.

It has been suggested that Parkinson's disease might be due to subclinical damage to the substantia nigra followed, after many years, by age related attrition of nigral neurones in the later decades of life ${ }^{3}$ This concept has been extended to a number of other neurological diseases such as dementia of Alzheimer's type, delayed amyotrophy in poliomyelitis and motor neurone disease. ${ }^{4}$ Post-encephalitic Parkinson's syndrome provides an ideal disorder from which evidence may be adduced to support or refute the concept of interaction between environmentally induced damage and age dependent loss of neurones.

\section{Patients and Methods}

Many of the English survivors of the pandemic of encephalitis lethargica were provided a designated facility for their chronic care in the Highlands Hospital, Winchmore Hill, London. Patients of all ages were admitted mainly between the years 1925 and 1935. Forty years ago there were about 300 patients and some of these were studied in detail by the late Dr. Purdon Martin. ${ }^{5}$ There are now only 11 survivors, all of whom have been seen by the authors on a number of occasions over the last 20 years and who were examined again in May, 1987.

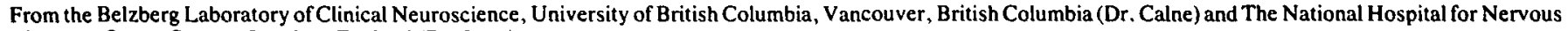
Diseases, Queen Square, London, England (Dr. Lees)

Received November 16, 1987. Accepted in final form March 17, 1988

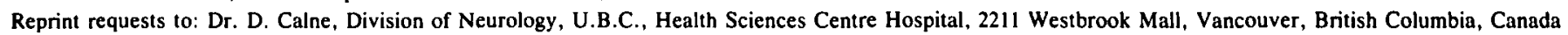
V6T IW5 


\section{Methods of Assessment}

The quantitation of parkinsonian disabilities has undergone changes since the introduction of levodopa therapy, previous assessments generally being descriptive and failing to provide numerical values. It was necessary, therefore, to draw some conclusions based on the memories of observers who had lifelong knowledge of the patients and from photographic records and narrative reports. G.F. a nurse involved in the care of the patients since 1931 and maintaining frequent social contact with the survivors, and Dr. J. Sharkey the physician in charge of the patients from 1946 to 1979 , kindly agreed to review the patients' current neurological status with us. Both had clear memories of the patients. In addition, five of the patients had been assessed using the Webster and Northwestern University Disability Scales in 1976 as part of a therapeutic study; these patients were re-evaluated.

Dr. Sharkey provided a general opinion as to whether significant clinical changes had occurred in the patients' parkinsonian disabilities between 1946 and 1979 and a retrospective semiquantitative evaluation of change in the patients between 1979, when he retired, and 1987. The scoring was based upon the following scale:

$0=$ no neurological deficit.

1 = mild but definite impairment of mobility.

2 = moderate difficulty in mobility which still allowed patients to assist in the operation of daily ward activities.

3 = patients no longer capable of helping in ward activities although still able to feed, dress and wash themselves and still able to stand and walk with a frame.

4 = patients totally dependent on support from the nursing staff and unable to stand without the assistance of at least one person.

All the surviving patients had substantial parkinsonian deficits. Their Columbia score ranged from 33-87, and their Hoehn and Yahr stages from III-V.

\section{Patients}

There were seven women and four men with ages on admission to the Highlands Hospital ranging from 12-37 years (mean 22). They were aged between 66 and 81 years (mean 74), with a duration of continuous in-patient care ranging from $40-56$ years (mean 49). All had considerable motor disabilities but none were severely demented. All could hear reasonably well, but one patient had a longstanding ambylopic eye. One patient had a hip fracture possibly contributing to her loss of mobility and another had gastrointestinal symptoms currently undergoing investigation. Three patients had upper motor neurone signs, but in none was there a definite history of stroke and $\mathrm{Dr}$. Sharkey reported that in one of them the pyramidal signs had been present for at least 30 years. Several of the patients had dystonia and some had contractures. Eight of the patients had bradykinesia, nine had rigidity, seven had tremor and ten had speech difficulties. Five of the patients were unable to walk at all and the others had varying degrees of difficulty. Two of the patients had developed supranuclear vertical gaze palsies. All the patients were still receiving anticholinergic medication and ten of them had participated in previous trials with L-dopa and/or bromocriptine, but none had been able to tolerate sustained treatment with either of these drugs because of adverse reactions.

\section{Results}

\section{Semi-quantitative Scores}

The range of values for 1979 was 1 to 2.5 (mean 1.5). Currently the scores range from 1.75 to 4.0 . The mean value is 3.3 . This represents a significant deterioration $(P<0.001)$. Although no clinical scoring protocol can be considered as linear, this arbitrary rating scale recorded a 2.2 fold increase in deficits over the period from 1979 to 1987 , representing a mean age change 66-74 years. There was no significant difference between men and women, and no correlation between age and deterioration. Table 1 summarizes the relevant observations on all patients.

\section{Photographic Records}

From Dr. Purdon Martin's meticulous records of the patients it was possible to discern a pattern of change which had taken place between the period of his observations in the 1960s and the present time. Figures 1 and 2 show a sample of photographs of two individuals (Patients 3 and 10 ) recorded with periods of 20 years between observations; considerable neurological deterioration has taken place.

\section{Narrative Reports}

If one takes together the comments by the late Dr. Purdon Martin, the opinions of Dr. Sharkey and G.F., the hospital chart and our own impressions, it is clear that some degree of motor deterioration has occurred in all patients except one (Patient 8) with a trend towards relative stability over the earlier years and a tendency to decline more markedly over the last twenty years. Patient 3 was carefully studied by Dr. Purdon Martin (Figure 1) at which time he was able to play cricket; sixteen years ago, however, he required assistance to walk and now at the age of 71 years he requires the support of two nurses even to stand. One of us (DBC) clearly recalls Patient l walking up and down the ward without assistance nineteen years ago, whereas now, at the age of 75 years, this patient needs the assistance of two nurses to stand. In neither case was there any extraneous factor contributing to the progressive motor dilapidation.

\section{Webster and Northwestern University Disability Scores}

Five of the patients had records of evaluations employing the Webster Disability Scale $^{6}$ and the Northwestern University Disability Scale ${ }^{7}$ (NUDS). For the Webster Scale, the mean value in 1976 was 18 (range 11-27) and in 1987 it was 21 (range 14-28). For the NUDS, the mean value in 1976 was 36 (range 20-45) and in 1987 it was 31 (range 24-41). The number of subjects was too small for any firm conclusion to be drawn from these limited results.

\section{Discussion}

About a third of patients with encephalitis lethargica died in the acute phases of the illness. Of the survivors, more than half were left with considerable neurological or psychiatric sequelae. About a third appeared to recover completely, and some of these subsequently developed Parkinson's syndrome. It is estimated that at least fifty per cent of survivors from the pandemic had a post-encephalitic Parkinson's syndrome. Kinnier Wilson found little or no deterioration in the severity of these parkinso- 
Table 1: Evaluation of Patients in 1987, with Retrospective Score Assigned for 1979 (see text)

\begin{tabular}{|c|c|c|c|c|c|c|}
\hline \multirow[b]{2}{*}{ Patient } & \multirow[b]{2}{*}{ Sex } & \multirow[b]{2}{*}{$\begin{array}{l}\text { Date of } \\
\text { Birth }\end{array}$} & \multirow[b]{2}{*}{$\begin{array}{c}\text { Date of } \\
\text { Admission }\end{array}$} & \multicolumn{2}{|c|}{ Retrospective } & \multirow[b]{2}{*}{ Comments } \\
\hline & & & & $\begin{array}{c}\text { Clinical } \\
\text { Score '79 } \\
\end{array}$ & $\begin{array}{c}\text { Clinical } \\
\text { Score '87 } \\
\end{array}$ & \\
\hline 2 & $\mathbf{F}$ & 1909 & 1946 & 2.0 & 3.5 & Prominent rigidity and foot dystonia \\
\hline 3 & $\mathbf{M}$ & 1916 & 1928 & 2.5 & 4.0 & Prominent rigidity and foot dystonia, leading to inability to stand \\
\hline 4 & $\mathbf{F}$ & 1917 & 1939 & 1.5 & 3.5 & Deterioration of speech, rigidity, balance, gait \\
\hline 7 & $\mathbf{F}$ & 1906 & 1933 & 1.0 & 3.5 & Rigid, bed bound \\
\hline 8 & M & 1908 & 1939 & 1.5 & 1.75 & Minimal gait deterioration \\
\hline 9 & $\mathbf{M}$ & 1914 & 1947 & 1.0 & 4.0 & Increased rigidity, decreased mobility \\
\hline 10 & $\mathbf{F}$ & 1917 & 1932 & 1.0 & 3.0 & Speech, tremor, balance and gait all deteriorated \\
\hline 11 & $\mathbf{F}$ & 1909 & 1944 & 2.0 & 4.0 & Speech, rigidity and mobility worse \\
\hline
\end{tabular}

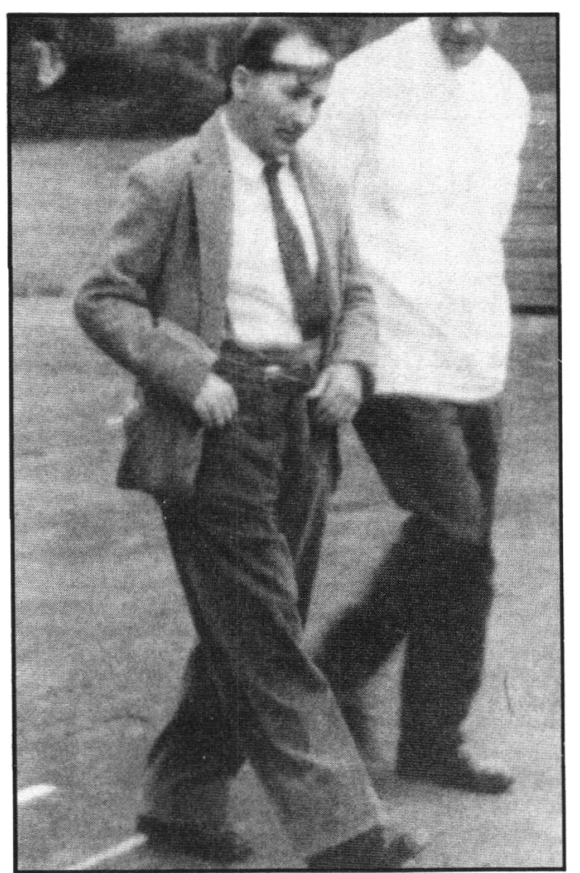

A

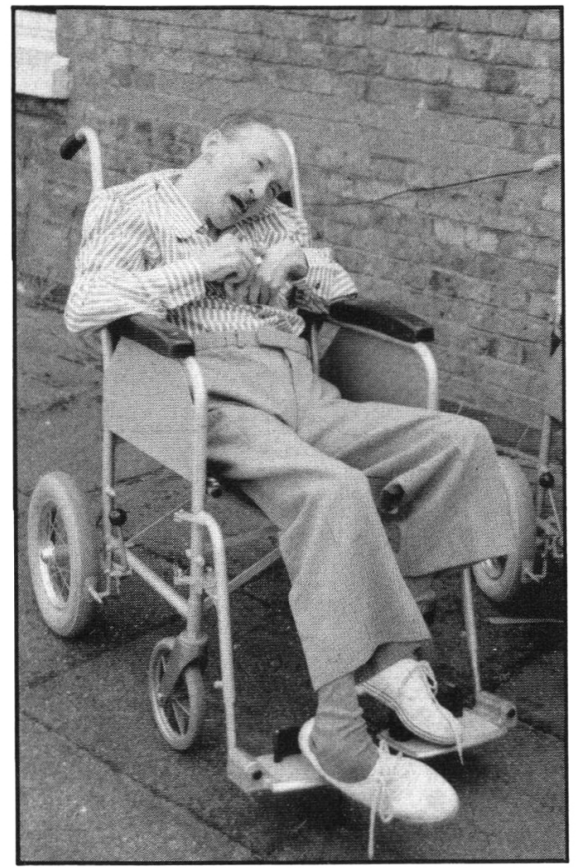

B

Figure I-Patient 3. A-photograph published

by Purdon Martin ${ }^{5}$ in 1967. B - appearance in 1987

nian states over the first ten to fifteen years, but noted that the outlook was less certain in the middle-aged or elderly cases. ${ }^{8}$ Duvoisin and $Y$ ahr ${ }^{9}$ studied 49 probable post-encephalitic patients in 1962 and reported that in those patients who had developed the malady 25-40 years before, there was either no progression or very slow deterioration. On the other hand, Duncan, ${ }^{10}$ who studied the natural history of post-encephalitic sequelae in 136 patients at the London Hospital at the time of the pandemic, was impressed with the progressive nature of the parkinsonian disabilities.

The findings in this study indicate that deterioration in motor function frequently occurs in late life following encephalitis lethargica in childhood or young adult life. Review of the patients' case notes confirms that all of them fulfill the recently proposed diagnostic criteria for encephalitis lethargica. ${ }^{11}$ The relatively uniform nature of the deterioration exceeded changes in motor function seen in normal elderly subjects ${ }^{12}$ and it was noteworthy that there were no comparable age-related changes in intellect or in the special senses.

There are several possible explanations for these findings. The population studied was unusual in that the patients were a selected institutionalized group of long term survivors who had been taking anticholinergic drugs for several decades. Dystonia was a prominent feature in several of the patients, undoubtedly contributing to their motor deficits. Rekindling of the original virus infection as a result of failure of immunological surveillance in old age cannot be excluded although post-mortem examination of the central nervous system in post-encephalitic patients had not revealed evidence of acute or chronic inflammatory change. ${ }^{12}$ It has recently been proposed that delayed 


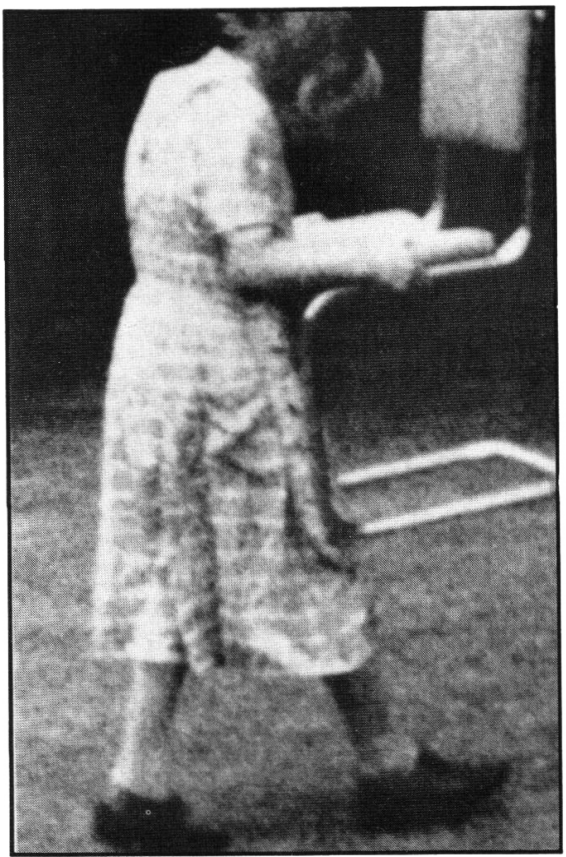

A

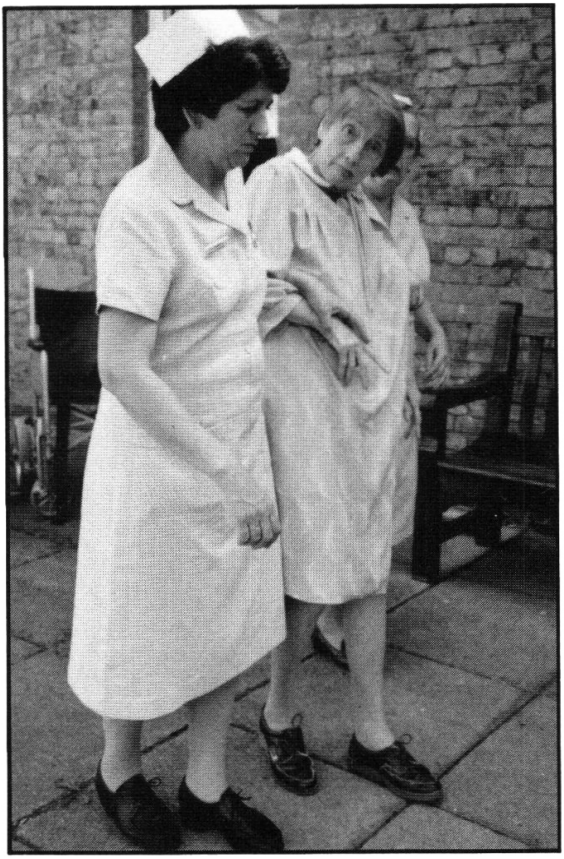

B

Figure 2-Patient 10.A-photograph published by Purdon Martin ${ }^{5}$ in 1967. B - appearance in 1987.

wasting and weakness in survivors from poliomyelitis might derive from selective dying back of those terminals which had formed as a result of collateral re-innervation in the acute stages of the disease. It is conceivable that a similar mechanism might be operative here. Alternatively the original viral infection may have caused subtle damage to neurons such that their "life expectation" was decreased. Another explanation is that the motor deterioration may have resulted from age-related decay of dopaminergic neurons superimposed on a background of previous damage related to the encephalitic illness.

The mechanism of age-related attrition of neurons is not understood. It is possible that in senescence, damage results from excessive production or inadequate removal of free radicals such as superoxide. This may also be the "final common pathway" of neuronal destruction in degenerative disorders such as Parkinson's disease, Alzheimer's disease and motoneurone disease. In an attempt to confirm or refute this hypothesis in Parkinson's disease a large prospective multicentre study of antioxidants is currently in progress. ${ }^{13}$

\section{ACKNOWLEDGEMENT}

This work was supported by the Dystonia Medical Research Foundation and the MRC of Canada. We are indebted to Dr. J. Sharkey, Dr. H. Caplan, Mr. G. Fox and Mr. M. Boodhoo for their help at Highlands Hospital. Susan Calne, RN, assisted in the evaluation of the patients.

\section{REFERENCES}

1. Howard RS, Lees AJ. Encephalitis lethargica. A report of four recent cases. Brain 1987; 110: 19-33.
2. Williams A, Houff S, Lees A, Calne DB. Oligoclonal banding in the cerebrospinal fluid of patients with postencephalitic parkinsonism. Journal of Neurology, Neurosurgery and Psychiatry 1979; 42: 790-792.

3. Calne DB, Langston JW. Aetiology of Parkinson's disease. Lancet $1983 ; 31: 1457-1459$.

4. Calne DB, Eisen A, McGeer E, Spencer P. Alzheimer's disease, Parkinson's disease, and Motorneuron disease: Abiotrophic interaction between aging and environment? The Lancet 1986; 2: 1067-1070.

5. Martin JP. The Basal Ganglia and Posture. London: Pitman Medical Publishing Co. Ltd., 1967.

6. Webster DD. Clinical analysis of the disability in Parkinson's disease. Mod Treat 1968; 5: 257-282.

7. Canter CJ, de la Torre R, Mier M. A method of evaluating disability in patients with Alzheimer's disease. J Nerv Mental Dis 1961; 133: 143-147.

8. Wilson SAK. Neurology. Edited by Bruce AN, London: Arnold 1940: 99-144.

9. Duvoisin RC, Yahr MD. Encephalitis and parkinsonism. Arch Neurol 1965; 12: 227-239.

10. Duncan, AG. The sequelae of encephalitis lethargica. Brain 1924; 47: 76-108.

11. Teravainen $\mathrm{H}$, Calne DB. Motor system in normal aging and Parkinson's disease. In: Katzman R, Terry RD (eds.). Neurology of Aging: Contemporary Neurology Series. F.A. Davis Company, Philadelphia 1981;85-109.

12. Gibb WRG, Lees AJ. The progression of idiopathic Parkinson's disease is not explained by age-related changes. Clinical and pathological comparisons with post-encephalitis parkinsonian syndrome. Acta Neuropathol 1987 (in press).

13. Shoulson I. Experimental therapeutics directed at the pathogenesis of Parkinson's disease. In: Calne DB (ed.) Handbook of Experimental Pharmacology: Drugs for the treatment of Parkinson's disease. Springer-Verlag, Heidelberg 1988 (in press). 